\title{
Modos de trabalhar e de ser na reestruturação bancária
}

CARMEM LIGIA IOCHINS GRISCI ${ }^{*}$ E VANIA GISELE BESSI

\section{Introdução}

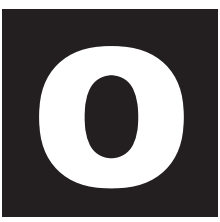

trabalho tem-se constituído inesgotável fonte de estudos. Atravessado pelas transformações econômicas, sociais e políticas e suas implicações sociais, configura-se como instigante campo de pesquisa. Uma série de fatores, entre eles, a reestruturação produtiva do trabalho que se consolidou na década de 1990, aliada à financeirização da economia, que possibilitou aos capitais deslocarem-se rapidamente, desviando recursos que antes eram destinados à produção de bens e serviços, para a especulação, colaborou para aumentar o número de desempregados e de excluídos do mercado de trabalho (CASTEL, 1998; POCHMANN, 1999; CASTELLS, 2000; ANTUNES, 2000, 2001).

O trabalho bancário, paradigmático em relação à reestruturação produtiva, passou a experimentar mudanças significativas, cada vez mais intensas. Tais mudanças afetaram os trabalhadores em seus modos de trabalhar e de ser (GRISCI, 2000). Uma lógica de instabilidade e imprevisibilidade resultante das contínuas reestruturações do trabalho, aliadas às novas tecnologias, fez com que o trabalho, em especial nas

* Doutora em Psicologia e Professora do PPGA da Escola de Administração da Universidade Federal do Rio Grande do Sul, Pesquisadora CNPq.

** Mestre em Administração e Professora da Universidade de Passo Fundo (UPF), Pesquisadora. 
instituições financeiras estatais, antes tido como trabalho para a vida toda, adquirisse um caráter de transitoriedade.

A tecnologia introduzida nas organizações interfere de inúmeras formas nos modos de trabalhar. Três possibilidades, entretanto, estão presentes no trabalho bancário atual: a automatização; o trabalho mais intelectualizado que demanda um trabalhador com capacidades e qualificações distintas das anteriormente demandadas e o aumento do desemprego. Ilustrativa dessas possibilidades, a empresa em estudo - doravante denominada empresa Xé uma instituição bancária centenária, de grande porte e de abrangência nacional. Sua longa história evidencia que sempre existiram mudanças na empresa, no entanto, tais mudanças nunca se haviam caracterizado pela velocidade inimaginável que as caracteriza atualmente. A partir da segunda metade da década de 90, com a introdução da tecnologia da informação, a reestruturação produtiva do trabalho se mostrou de modo veemente nessa empresa. A empresa $X$ atua em diferentes setores: habitação, saneamento urbano, empréstimos, carteiras hipotecárias, cobranças, pagamentos, operacionalização de ações sociais designadas pelo governo federal e incentivo à poupança popular. Atuando sob a lógica da segmentação de clientes, a empresa $X$ dispunha, no momento da realização desta pesquisa, de 1950 agências em todo o território nacional e contava com 55.000 funcionários.

Em decorrência da reestruturação produtiva do trabalho, a empresa $X$ passa, então, a reduzir seus quadros de funcionários, visando adequar-se à economia nacional em sua fase de estabilização. Por tratar-se de uma empresa pública, o processo de demissão distingue-se do processo da iniciativa privada pelo uso de uma ferramenta denominada Programa de Apoio à Demissão Voluntária ou Incentivada - PADV ou PADI que oferece aos trabalhadores alguns incentivos para que solicitem seu desligamento da empresa. Na empresa X ocorreram três edições do PADV nos anos de 1996, 2000 e 2001. 
Diante da questão teórica que hoje se coloca em relação às transformações desencadeadas no mundo do trabalho, em especial no trabalho bancário, e tomando-se o PADV como uma das ferramentas de gestão na reestruturação produtiva do trabalho da empresa $X$, torna-se pertinente e relevante a seguinte questão de pesquisa: como a reestruturação produtiva do trabalho na empresa $\mathrm{X}$ afetou os trabalhadores que aderiram à terceira edição do PADV ocorrida em 2001?

Esta pesquisa caracteriza-se como um estudo de caso, tendo em vista a estratégia de buscar conhecimento em profundidade de uma realidade ou de um fenômeno social, sendo conduzido em detalhes e, com freqüência, baseado em várias fontes de dados.

Os sujeitos desta pesquisa são os que aderiram à terceira edição do PADV, em 2001, funcionários da área de RH e da gestão de agências e/ou áreas de apoio, envolvidos na implantação e acompanhamento do referido programa. Destes, dezesseis foram entrevistados via entrevistas individuais semi-estruturadas: três funcionários da área de recursos humanos, cinco ocupantes de cargos de gestão, e oito sujeitos que aderiram ao PADV. Além dos entrevistados, participaram da pesquisa, via questionários, mais 104 sujeitos dos estados do Rio Grande do Sul e de Santa Catarina.

A seleção dos entrevistados ocorreu de diferentes formas: da área de RH foram entrevistados aqueles que trabalharam no Centro de Orientação Profissional junto aos desligados no PADV; dos gestores fez-se a composição de um grupo representativo quanto ao tempo de empresa, ao gênero, à idade e à área de atuação (agências e áreas de apoio); dos sujeitos que aderiram ao PADV, entrevistou-se aqueles que responderam positivamente à pergunta contida no questionário: "Você estaria disposto a participar de nova etapa desta pesquisa?" Mais de $70 \%$ dos sujeitos que aderiram ao PADV nos estados do Rio Grande do Sul e de Santa Catarina residiam em cidades do interior, portanto, por limitações financeiras e de tempo, não foi possível estender as entrevistas da pesquisa a essas cidades, concentrando- 
se a coleta de dados, através de entrevistas, em Porto Alegre e em Florianópolis. A escolha dos entrevistados objetivou uma composição que fosse representativa quanto ao gênero, ao tempo de empresa e à função exercida.

A coleta de dados foi desenvolvida, portanto, através de três diferentes instrumentos: entrevista semi-estruturada, questionário e fonte documental. Optou-se por utilizar várias fontes de dados, uma vez que isso permite o confronto dos dados que eventualmente venham a se repetir e validá-los (YIN, 2001). Os questionários foram aplicados no período de setembro a novembro de 2001, e as entrevistas foram realizadas no período de janeiro a abril de 2002.

\section{Considerações sobre o tema}

A organização do trabalho, entendida como sendo: "por um lado, a divisão do trabalho: divisão de tarefas entre os operadores, repartição, cadência, enfim, o modo prescrito; e por outro lado, a divisão de homens: repartição das responsabilidades, hierarquia, comando, controle, etc." (DEJOURS, 1994, p.125), exerce profunda influência nos modos de trabalhar e de ser dos sujeitos do trabalho. Tais influências são estendidas para a vida como um todo, (re)configurando os modos de ser e de agir dos sujeitos, afetandoos física e psiquicamente. Conforme se verá a seguir, a literatura aponta para novas formas relativas ao contexto do capitalismo e à organização do trabalho. As novas formas de estruturar o trabalho, com o aumento da informatização e da intelectualização, passam a aliar no processo de trabaIho, o trabalho material e imaterial.

O trabalho imaterial seria o que se extingue no momento de sua produção, agregando características pessoais do próprio trabalhador. Tratase de capacidades de mobilização, cooperação e criação que são dificilmente comandadas ou passíveis de controle externo ao trabalhador. Lazzarato 
e Negri (2001) argumentam que o trabalho imaterial é o que se encontra no cruzamento, seria a interface da nova relação produção/consumo, sendo que cabe ao trabalho imaterial ativar e organizar a relação produção/ consumo.

A nova relação, acima referida, é caracterizada por Lazzarato (2002) ${ }^{1}$ como uma mudança da lógica vigente na produção taylorista-fordista, que se baseava no ciclo produção/mercado/cliente, e que, a partir da produção flexível, passa a se dar no sentido cliente/mercado/produção. Essa idéia é corroborada por Santos (2002, p.48), ao afirmar que "as empresas hegemônicas produzem o consumidor antes mesmo de produzir os produtos. Um dado essencial do entendimento do consumo é que a produção do consumidor, hoje, precede à produção dos bens e dos serviços". Para Hardt e Negri (2001), essa mudança de lógica corresponde a uma melhor comunicação entre a produção e o consumo de mercadorias, ou seja, inicia-se uma passagem de informação entre a fábrica e o mercado, que não era possibilitada pelo modelo taylorista-fordista, uma vez que "o modelo fordiano construiu uma relação relativamente 'calada' entre a produção e o consumo" (HARDT e NEGRI, 2001, p.310).

Esse novo ciclo apresentaria, como principais características, a produção em ciclo curto e a produção de subjetividade (LAZZARATO, 2002). Daí ser o trabalho imaterial ponto de fundamental importância nessa nova relação, que, além de produzir objetos concretos, produz informação, conhecimento, serviços, valores. E que é definido como imaterial também porque incide sobre algo imaterial, que é a subjetividade humana, ou seja, as formas de vida, as maneiras de sentir, de amar, de perceber, de viver.

O trabalho imaterial, portanto, demandaria um novo tipo de trabalhador, diferente do "operário massa" do modo de produção taylorista-fordista, que se caracterizava como "duplamente massificado: pelos contingentes de

1 Curso de curta duração intitulado "Trabalho Imaterial e Subjetividade", ministrado por Maurizio Lazzarato, no Instituto de Psicologia da Universidade Federal do Rio Grande do Sul, em novembro de 2002. 
forças de trabalho concentrados nas grandes fábricas e pela tendencial indistinção, do ponto de vista da divisão técnica do trabalho, de suas características pessoais, subjetivas" (COCCO, 2001, p.18). A nova configuração do trabalho demanda que o trabalhador seja mobilizado não apenas como objeto de trabalho, pois é chamado a ser também sujeito desse processo, sendo suas características pessoais, antes massificadas, agora tidas como fator competitivo para as empresas, no sentido de que, para se produzir o bem imaterial, é necessário construir o bem imaterial, que se constitui no desejo, opiniões, gosto das pessoas, ou seja, a construção do cliente. Hardt e Negri (2001) corroboram essa idéia, mencionando ainda como característica do trabalho imaterial a mobilização afetiva necessária ao trabalhador, sendo que "o que o trabalho afetivo produz são redes, formas comunitárias, biopoder" (HARDT e NEGRI, 2001, p.314).

Ante o exposto até então, o trabalho imaterial passa a ter papel preponderante, em especial, para o setor de serviços em que a comunicação entre produção e consumo sempre se verificou de forma mais intensa, configurando o desenvolvimento do que Lazzarato e Negri (2001), utilizando-se de nomenclatura cunhada por Christian du Tertre ${ }^{2}$, definem como "relação de serviço". Tal relação ocorre pela superação da organização taylorista dos serviços, caracterizando-se por uma maior intervenção do consumidor na constituição do produto:

O produto 'serviço' torna-se uma construção e um processo social de 'concepção' e de inovação. Nos serviços, os empregos de back-office (o trabalho clássico em serviços) diminuem, enquanto aumentam os de front-office (as relações com os clientes). Existe, portanto, um deslocamento da pesquisa humana em direção ao exterior da empresa (LAZZARATO e NEGRI, 2001, p. 44-45).

2 "Trata-se de dois relatórios que du Tertre apresentou ao longo do ciclo de palestras 'Conceitos de trabalho no início do século XXI' (Paris: Ministério da Ciência e Tecnologia) em meados da década de 1980" (Lazzarato e Negri, 2001, p.44). 
Face ao trabalho imaterial, (re)organizam-se teorias e práticas de gestão, uma vez que o modo de trabalho capitalista global requer de quem trabalha, além de qualificação e performance, características como iniciativa, mobilidade, cooperação, domínio do processo, capacidade de prever e eliminar falhas, capacidade de comunicação e de interação com o próprio trabalho e com os demais trabalhadores e, principalmente, com os clientes.

Os métodos de gestão e de gestão de pessoas seriam, portanto, os fios condutores das organizações e, por conseqüência, afetariam a vida daqueles que trabalham nas mesmas. Segundo Chanlat (2000, p.119): "por modo ou método de gestão entende-se o conjunto de práticas administrativas colocadas em execução pela direção de uma empresa para atingir os objetivos que ela se tenha fixado". Nesse sentido, o método de gestão compreende o estabelecimento de condições de trabalho, a organização do trabalho, a natureza das relações hierárquicas, o tipo de estruturas organizacionais, os sistemas de avaliação e controle dos resultados, as políticas para a gestão de pessoas, enfim, os objetivos, os valores e a filosofia da gestão de uma forma geral.

Existem vários métodos ou modos de gestão, sendo que podem ocorrer algumas variações de tipificações conforme a análise de diferentes autores. Chanlat (2000) utiliza a seguinte tipificação:

1) modo de gestão tayloriano e neotayloriano (que inclui o modo fordiano) - iniciado a partir de Taylor, caracteriza-se principalmente pela divisão do trabalho, produção sob premência de tempo, tarefas repetitivas, direito de expressão reduzido, e até nulo, divisão entre concepção e execução e sistemas de controle elaborados;

2) modo de gestão tecnoburocrático - inicialmente descrito por Weber, caracteriza-se por uma pirâmide hierárquica desenvolvida, divisão do trabalho parcelada, regulamentação escrita onipresente, importância aos especialistas e técnicos, controles sofisticados, comunicação difícil entre os escalões da empresa, centralização do poder; 
3) modo de gestão da excelência (ou qualidade total) - engloba as novas práticas administrativas, baseando-se na noção de produzir melhor que os concorrentes, enfatiza a primazia do êxito, a supervalorização da ação, a obrigação de ser forte, a adaptabilidade e o desafio permanentes, recompensas materiais individualizadas, polivalência da mão-de-obra e recrutamento seletivo.

A passagem de um modelo a outro não se dá de forma automática e acontece influenciada por fatores como: fatores internos à organização (decisões estratégicas, cultura, etc.), fatores externos (competição com outras organizações, por exemplo), contexto político, contexto cultural e contexto social (CHANLAT, 2000).

Gestão de pessoas, como comumente tem sido chamada, segundo Davel e Vergara (2001, p.47), é "uma construção social baseada em uma visão particularizada de organização e de pessoa, variando no tempo e no espaço". Desse modo, a forma como as pessoas são geridas sofre influência das diretrizes da empresa, além de estar também fortemente presente a questão pessoal dos gestores, de acordo com o tipo de liderança que exercem, sua personalidade, etc. Considerando-se que as pessoas participantes de uma organização são as responsáveis pela criação, inovação e vitalidade das ações, as políticas de gestão de pessoas têm uma importância singular para as empresas.

A gestão de pessoas acompanha as transformações ocorridas na gestão empresarial como um todo, já que a forma como são conduzidas as políticas de gestão de pessoas está intimamente relacionada com a visão acerca do "ser trabalhador". Ignorando aspectos da vida do trabalhador enquanto ser integral, a gestão, não raro, tenta conseguir sua mobilização total para o projeto da organização (CHANLAT, 1996). Algumas estratégias são utilizadas deliberada ou naturalmente concebidas, de modo a fazer com que os trabalhadores sintam-se como membros de uma grande família, filhos de uma mãe caridosa, tal como mostra Pagès et al. (1993), acerca do poder das organizações sobre os trabalhadores. 
Segundo os autores (PAGÈS et al., 1993), a fusão entre empresa e trabalhadores seria possível, na medida em que a organização hipermoderna ${ }^{3}$ promove o que eles chamam de "desterritorialização" do indivíduo.

A desterritorialização é o conjunto dos mecanismos que consistem em separar o indivíduo de suas origens sociais e culturais e destituí-lo de sua história pessoal para reescrevê-la no código da organização, em desenraizálo de sua terra originária para melhor enraizá-lo no solo empresarial, em apagar suas referências originais para substituí-las por outras mais conformes aos interesses da empresa (PAGÈS et al., 1993, p. 119).

Lima (1995) analisa as novas políticas de gestão de pessoas como estratégias organizacionais no sentido de aumentar a dependência dos trabalhadores em relação à empresa, configurando o que ela denomina como "formas de sedução da empresa". Algumas características dessas novas políticas acabam configurando-se em um ambiente atraente e sedutor que as empresas disponibilizam aos seus supertrabalhadores, os que conseguirem passar pelos rigorosos processos seletivos. Lazzarato e Negri (2001, p.25) endossam essa percepção afirmando que: "como prescreve o novo management, hoje, 'é a alma do operário que deve descer da oficina'. É a sua personalidade, a sua subjetividade, que deve ser organizada e comandada".

No âmbito deste artigo, utiliza-se o conceito de subjetividade, procurando entender como os trabalhadores bancários percebem e reagem ante as novas demandas de características e de novos modos de ser e de trabaIhar advindos dos constantes processos de reestruturação pelos quais a empresa X passou e passa.

Entende-se subjetividade não como sinônimo de interioridade, mas como algo construído a partir do social e como construtor do social. Conforme Pelbart (2000, p.37), a subjetividade "não é algo abstrato, trata-se da

3 Organização hipermoderna é o termo utilizado pelos autores para designar a grande organização representada, em seu estudo, pelas multinacionais. 
vida, mais precisamente, das formas de vida, das maneiras de sentir, de amar, de perceber, de imaginar, de sonhar, de fazer, mas também de habitar, de vestir-se, de embelezar-se, de fruir, etc.". Modos de subjetivação dizem respeito, portanto, à construção de modos de viver a partir da concretude do mundo. Desde esta lógica, "a subjetividade não é ponto de partida, mas é resultante de múltiplos processos, agenciamentos coletivos" (FERREIRA NETO, 2000, p.107). Portanto, os modos de subjetivação são construídos atravessados por processos concretos do mundo, num imbricamento entre o fora, do mundo exterior e o dentro, do sujeito. Como refere Naffah Neto (1998, p.70-71):

... o mundo não é tão somente exterior, nem tão somente interior; está sempre fora e dentro ao mesmo tempo ou, melhor dizendo, constitui-se numa imbricação de um exterior e de um interior, fluindo e refluindo por movimentos de projeção e introjeção. (...) Ao fora aprendemos a chamar de mundo; ao dentro de subjetividade.

Partindo-se do exposto, a reestruturação produtiva do trabalho bancário que, na empresa $X$, teve como uma de suas principais conseqüências a implantação dos PADVs, pode ser tomada como modo de subjetivação ou de produção de estilos de vida ou de modos de existência. Isso porque, através da tecnologia da informação, intensificação do trabalho e necessidade de vender produtos aos clientes, a reestruturação produz sujeitos que necessitam de características pessoais outras em relação às características pessoais próprias, ou condizentes com as dos trabalhadores considerados "antigos" na empresa.

A seguir trata-se, mais especificamente, do trabalho bancário no Brasil.

\subsection{O trabalho bancário no Brasil}

É desde a perspectiva do trabalho imaterial, das novas políticas de gestão e de gestão de pessoas e da subjetividade, que se procede a uma 
incursão referente ao sistema financeiro e ao trabalho bancário, bem como à reestruturação produtiva do trabalho bancário e o desemprego que dela provém.

O trabalho bancário assume um status diferenciado no mercado financeiro, uma vez que deixa de atuar simplesmente de maneira a operacionalizar pequenos trabalhos burocráticos, passando a uma posição de consultoria de negócios, sendo demandadas características próprias do trabalho imaterial (JINKINGS, 1996). Neste sentido, as instituições financeiras acabam sendo o instrumento que proporciona a autonomia do capital, através do trabalho bancário, que sofre intensa reestruturação.

Estudos realizados por diversos autores a respeito das transformações do capitalismo (CASTELLS, 2000; COCCO, 2000; HARVEY, 2001, entre outros) convergem na análise de que este passa há algum tempo por um profundo processo de reestruturação que afeta dramaticamente o modelo taylorista-fordista de produção, em razão da busca por uma maior flexibilidade, maior descentralização devido à estruturação das empresas em rede e um controle cada vez maior da força de trabalho (CASTELLS, 2000).

A análise de Harvey (2001) da crise do modelo taylorista-fordista de produção leva-o à conclusão de que esta se verifica pelo excesso de rigidez, especialmente em relação aos investimentos de capital fixo e à administração de pessoas. Nas décadas de 1960/1970, a flexibilização estava unicamente no setor monetário, o que levou a uma onda inflacionária. O desencadeamento do processo inflacionário conduziu o capital a repensar suas estruturas, buscando a reestruturação. Nas palavras de Harvey (2001, p. 137):
(...) as corporações viram-se com muita capacidade excedente inutilizável (principalmente fábricas e equi- pamentos ociosos) em condições de intensificação da competição. Isso as obrigou a entrar num período de racionalização, reestruturação e intensificação do con- trole do trabalho. 
A busca pela superação desse modelo em direção à acumulação flexível "se apóia na flexibilidade dos processos de trabalho, dos mercados de trabalho, dos produtos e padrões de consumo" (HARVEY, 2001, p.140). Além disso, as inovações tecnológicas buscam a diminuição da dependência do capital em relação ao trabalhador, uma vez que incorporam às máquinas e ferramentas o saber informal do trabalhador, através de processos de automação. Segundo Harvey (2001), ainda como conseqüências dessa nova fase, apresenta-se uma mão-de-obra que se tem tornado cada vez mais barata, e trabalhadores que se sujeitam a cargas de trabalho cada vez maiores, bem como maior concentração de renda.

Tal panorama de modificações provoca mudanças no agir do trabaIhador bancário, que tem de constituir-se em sujeito de respostas cada vez mais rápidas, uma vez que o seu trabalho se torna, a cada dia, mais ágil, acompanhando a velocidade dos computadores. O bancário tradicional, autodenominado antigo, que tinha como principal meio de trabalho a moeda, começa a ceder espaço para um novo profissional que tem na informação sua principal ferramenta de trabalho (DIEESE, 2001b), sendo dele demandadas características próprias do trabalho imaterial.

Há ainda uma significativa mudança no status da profissão de bancário, constantemente ameaçada pelo desemprego advindo de processos de automatização de serviços. Segundo dados do Ministério do Trabalho, em janeiro de 1991, a categoria dos bancários contava com 754 mil trabalhadores no território nacional. Em outubro de 2000, o número de funcionários do setor girava em torno de 394.500 (COSTA, 2001). No que tange à redução no mercado de trabalho bancário correspondente à década anterior, Segnini (1999) já a relacionava à eliminação de postos de trabalho superpostos, superposição de agências, reestruturação das formas de gestão, fusão de postos de trabalho, bem como ao uso intensivo de tecnologias da informação. 
Estudos (ACCORSI, 1990; JINKINGS, 1996; LARANGEIRA, 1997; SEGNINI, 1998, 1999; GONÇALVES FILHO, 2000; PENELLA, 2000; CORAZZA, 2000; GRISCI, 2000, 2001, 2002; RUFFEIL, 2002; BESSI, 2003) evidenciam que o trabalhador bancário vive, há algumas décadas, sob a influência de novas forças que o tomam de assalto. Anteriormente à onda mais intensa de automação bancária, iniciada no Brasil, nas décadas de 1980/1990, o trabalho bancário tinha uma conotação diferenciada da atual. A natureza do trabalho, o seu produto e o status da função de bancário proporcionavam a esse trabalhador a percepção de que o seu trabalho tinha uma importância elevada para a sociedade.

Acrescenta-se a isso o fato de que, conforme salienta Segnini (1998, p.21):

O sistema financeiro brasileiro é um dos mais informatizados do mundo e a categoria bancária apresenta alto nível de escolaridade, sobretudo se comparada com o baixo grau de escolaridade da população e dos trabalhadores dos setores primários e secundários da economia. Portanto, trata-se de uma categoria altamente escolarizada no contexto de um país que apresenta elevado déficit educacional, no qual somente $11,2 \%$ da população concluiu o terceiro grau.

Até 1960, as transformações ocorridas no trabalho bancário foram lentas, porém caracterizadas pela busca da racionalização e mecanização do trabalho bancário. Até a Reforma Bancária de 1964, os bancos atuavam de maneira segmentada e regionalizada, a maioria de pequeno porte. De acordo com Jinkings (1996) a Reforma Bancária (Lei n. 4595, de 31. 12. 1964), a Reforma do Mercado de Capitais (Lei n. 4728, de 14.07.1965) e o Plano de Ação Econômica do Governo (1964/1966) criaram mecanismos legais de controle e fiscalização pelo Estado, das instituições públicas e privadas do sistema financeiro; entre outros, estabeleceram a formação de 
instituições financeiras especializadas na captação e aplicação de recursos a médio e longo prazo, institucionalizaram a correção monetária na remuneração de aplicações para incentivar a poupança.

A intensificação da industrialização demandou novas adaptações do setor bancário a fim de que pudesse contribuir para o desenvolvimento do país, uma vez que havia uma demanda cada vez maior por crédito. Dessa forma, foi necessário que os bancos se estruturassem de forma semelhante às indústrias, adotando modelos de organização taylorista/fordista (PENELLA, 2000), sendo introduzidas a mecanização, a padronização, a normatização e a rotinização dos procedimentos bancários, compondo o cenário propício para o início de mudanças tecnológicas e organizacionais mais profundas. Novas respostas são exigidas aos bancários, em que a cobrança por produtividade passa a ocorrer de forma mais intensa.

Ainda na década de 60, a tecnologia de base microeletrônica é introduzida no sistema financeiro nacional configurando-se em mais um feixe das complexas inovações organizacionais no setor bancário que, associada a novos modelos de gestão, gerou impactos na produtividade, nas condições de trabalho e no perfil dos trabalhadores desse setor. Assim, diferentemente de alguns setores da economia que começavam a utilizar essas tecnologias, o sistema financeiro adota padrões tecnológicos de primeiro mundo (SEGNINI, 1998; CORAZZA, 2000).

Nas décadas seguintes, em decorrência da demanda do mercado e da crescente concorrência entre bancos, passa a ocorrer, também, uma diversificação das atividades bancárias, multiplicando o leque de serviços. O atendimento ao público e a venda dos produtos já começa a fazer parte do cotidiano dos trabalhadores, ainda de forma incipiente: "as agências passam a assumir papel de destaque no conglomerado financeiro ao qual se encontram vinculadas, transformando-se em 'postos de venda' do grupo financeiro. Para atrair clientes, aperfeiçoam-se os serviços de atendimento ao público" (Jinkings, 1996, p.44). 
Diante desse cenário, pode-se constatar a mudança do perfil do bancário: do contador com conhecimento sobre todo o processo de trabalho no banco, com perspectiva de carreira, detentor de um status social, a um funcionário pouco qualificado, fragmentado em tarefas simples e repetitivas. "O perfil dos bancários altera-se, passando a representar uma categoria jovem, e a 'profissão' bancário torna-se transitória, servindo apenas como um meio para terminar os estudos" (PENELLA, 2000, p. 50).

Cabe salientar que, a partir da década de 1980, a implantação e difusão do sistema on line, caracterizado pela criação dos sistemas de apoio às decisões e implantação dos terminais de consulta aos clientes, não somente intensificou o trabalho bancário, pois veio acompanhado de redução de pessoal nos trabalhos de retaguarda, como também serviu de suporte a um controle maior. Com a implantação dos sistemas on line, a natureza do trabalho também se altera:

o tradicional fluxo de papéis, documentos manipulados e contabilizados no trabalho de escrituração do movimento diário dos bancos, vai sendo substituído por dados armazenados e manipulados em sistemas eletrônicos, baseados em computadores. Informações passam a ser a matéria prima dos bancos (Ruffeil, 2002, p. 103).

Em trabalho desenvolvido a respeito da reestruturação produtiva do trabalho bancário no Brasil, divulgado no site do DIEESE, o processo de reestruturação pode ser dividido em duas etapas: a reestruturação ou "ajustes para dentro" (reorganização interna) e a reestruturação ou "ajustes para fora" (DIEESE, 2001b).

O processo de reestruturação para dentro (reorganização interna) dos bancos brasileiros ocorre mais intensamente a partir da segunda metade da década de 80, e caracteriza-se pela redução de custos operacionais, intensificação da automação, desenvolvimento e incentivo ao auto-atendimento, 
mudanças nas técnicas de gestão, redução de postos de trabalho e terceirização. Tais ajustes ainda acontecem no início da década de 90, quando ações empreendidas pelo governo federal visando ao ajuste da economia propiciam a queda da inflação que chegava a patamares próximos a $25 \%$ para cerca de $1 \%$.

Conforme atestam os estudos de Segnini (1998) os impactos do processo de difusão da automação bancária, que remonta à década de 60, e as citadas desregulamentações não se fizeram notar na estrutura de empregos no setor financeiro até 96, já que até essa época observava-se a expansão do número de agências e de trabalhadores. Para a autora, isso decorre do fato de a inflação elevada constituir-se na principal fonte de lucratividade dos bancos, até julho de 1994, quando ocorreu o Plano Real. Com a estabilização dos preços, resultante da implementação do Plano Real, que objetivava a estabilização econômica, a partir de julho de 1994, o setor bancário é profundamente afetado tanto em termos institucionais quanto em termos econômicos: "a participação das instituições financeiras no PIB, que atingira a média de 13,37\% no período 1992-1994, reduziu-se a 6,94\% em 1995 em decorrência, em grande medida, da queda substancial das receitas inflacionárias dos bancos comerciais" (MARUCCl e MACHADO-DASILVA, 2000, p. 6).

Os processos de queda de inflação e dos investimentos financeiros, por conseqüência, despertaram nos bancos, principalmente nas grandes instituições privadas de varejo, a necessidade de se prepararem para sobreviver num ambiente econômico sem inflação (LARANGEIRA, 1997).

Com a estabilização da economia, os bancos tiveram queda substancial das receitas decorrentes de ganhos inflacionários, proporcionadas pelo floating. ${ }^{4}$ No primeiro semestre de 1994, os mais importantes bancos brasileiros obtiveram $63,4 \%$ de suas receitas do floating. No mesmo período de 1995, essa proporção caiu para 4.7\% devido à crescente exposição à 
competição internacional (SALINAS, MAÇADA E SANTOS, 1998; DIEESE, 2001a). Essa queda abrupta fez com que as instituições bancárias reavaliassem seus custos operacionais, desencadeando uma série de processos de reestruturação dos bancos no cenário nacional, o que pode ser ilustrado pela intensificação dos processos de informatização nos bancos, conforme dados estatísticos da FEBRABAN (2001):

As transações automatizadas dos processos bancários já representam $74,7 \%$ do total, enquanto as realizadas com intervenção de funcionários nas agências ou por telefone passaram a representar apenas 25,3\%. O horário de atendimento nas agências condiciona cada vez menos o volume de serviços prestados aos clientes, que utilizam com crescente intensidade os demais canais disponíveis por períodos bem mais amplos, muitos em tempo integral. (...) merece especial destaque o crescimento das transações por computadores - via internet ou home e office banking - por equipamentos de autoatendimento e as de origem interna, que são aquelas executadas pelo próprio banco para atender a demanda dos clientes - pagamentos programados, débitos de financiamentos, de tarifas etc.

Conforme avalia Segnini (1998), a implantação de políticas econômico-financeiras governamentais possibilitou aos bancos se reestruturarem, em termos operacionais, mantendo a capacidade de obtenção de lucros através de redução de custos operacionais com largo uso da informática, que redimensionou os modos de comunicação, inclusive com a clientela, a partir da adoção de artifícios como o home bank.

Somam-se a isso, ainda por volta de 1990, duas alterações institucionais que aceleraram as mudanças nos bancos, provocando, assim, maior concorrência no mercado bancário brasileiro: a institucionalização da figura do banco múltiplo e o fim da exigência da carta patente para se abrir uma instituição financeira. 
Uma segunda etapa da reestruturação do trabalho bancário se dá a partir do final de 1994, quando os bancos que atuam no sistema financeiro brasileiro intensificam o "ajuste para fora" em decorrência do cenário exposto. Tais ajustes direcionam-se ao desenvolvimento de novos produtos e serviços, ao tratamento diferenciado da clientela, conforme o perfil de renda e potencial de consumo dos serviços e produtos financeiros. Essa etapa acontece principalmente por meio de processos que envolvem transferência do controle acionário, intervenção ou liquidação por parte do Banco Central e incorporação por outra instituição financeira.

Mais recentemente, no final da década de 90, a grande inserção de bancos internacionais, encampando bancos nacionais, é outro processo que vem a se somar aos ajustes para fora (DIEESE, 2001b). Nomes expressivos do cenário financeiro internacional, como o inglês Hong Kong \& Shangai Bank, os espanhóis Santander e Bilbao Viscaya, os bancos Espírito Santo, de Portugal e Crédit Agrícole, da França, são exemplos de instituições que vêm disputar mercado com os bancos nacionais (SALINAS, MAÇADA E SANTOS, 1998). A entrada dos bancos estrangeiros no país traz consigo uma nova concepção de serviço bancário, uma vez que essas instituições têm como uma de suas peculiaridades a prestação de assessoria aos clientes e não clientes, para auxiliá-los na aplicação de seus recursos. As conseqüências negativas de todas essas medidas se ilustram em larga escala nos indicadores de redução de postos de trabalho no setor bancário, bem maior desgaste físico e mental da força de trabalho (LARANJEIRA, 1997).

A seguir, apresenta-se o resultado da pesquisa, enfatizando, primeiramente, os principais aspectos da reestruturação produtiva do trabalho pelos quais a empresa $X$ passou, ao longo do tempo e, em seguida, como a reestruturação produtiva do trabalho na empresa $X$ afetou os trabalhadores que aderiram à terceira edição do PADV ocorrida em 2001. 


\section{A reestruturação produtiva do trabalho na empresa $x$}

No início da década de 1990, foram demitidos cerca de dois mil funcionários pelo presidente que à época assumia a empresa $X$. Tal ato politicamente imbuído do que foi apontado como "a caça aos marajás do serviço público no país", foi significativo num período que trazia consigo as primeiras ações em direção à reestruturação produtiva dos bancos brasileiros (DIEESE, 2001b), os primeiros passos na criação do banco múltiplo (DIEESE, 2001a), bem como a promoção dos principais ajustes na economia, que proporcionaram a abertura de fronteiras à economia externa. Neste período ainda, os bancos, de uma maneira geral, empreenderam ações intensas no sentido de se adaptarem a um ambiente econômico de queda da inflação (LARANGEIRA, 1997; SEGNINI, 1999), devido aos constantes planos de estabilização econômica empreendidos pelos diferentes governos (MARUCCI E MACHADO-DA-SILVA, 2000).

Tais demissões representaram um marco na história da empresa $X$ onde existia uma cultura de estabilidade, uma vez que os funcionários não vislumbravam a possibilidade de que pudessem ser demitidos. Embora fossem contratados em regime de Consolidação das Leis Trabalhistas - CLT -, não se tratando, portanto, de funcionários estáveis, prevalecia um sentimento de estabilidade, que foi profundamente abalado.

Em outubro de 1992, a empresa X declara-se em crise, identificada em todos os seus segmentos como a "mais profunda crise de toda a sua história", sendo preciso, "urgentemente, submetê-la a um programa de saneamento", encarado como um desafio que proclamava por um "tempo de esforço e sacrifício", conforme expresso em documento da empresa. Indícios da crise são identificados nos aspectos econômico-financeiros; operacional e tecnológico (baixo nível de informatização e a precariedade dos serviços ofertados); administrativo (baixo índice de produtividade e descompromisso com o processo de qualidade); e político-institucionais. 
Foi então que, a partir de tal diagnóstico, em novembro de 1992 foi lançado um programa de qualidade que tinha como objetivo o fortalecimento da empresa e seria implementado no decorrer do ano seguinte. $\mathrm{O}$ Programa de Qualidade Total, lançado em 1993, em síntese, buscava "homogeneização de objetivos e conseqüente homogeneização dos modos de ser e trabalhar" (GRISCI, 2000, p.185). As ações previstas no programa foram implementadas nos anos de 1993 e 1994.

A partir de 1995, no sentido de intensificar os ajustes dos processos de trabalho e o direcionamento da empresa, foi lançado o Programa de Racionalização e Competitividade - PRC. O lançamento do PRC efetuouse em um período marcado pela queda dos rendimentos dos bancos, proporcionada pela diminuição abrupta dos rendimentos bancários advindos do "floating".

Uma das finalidades do PRC era buscar a transformação da estrutura hierárquica da empresa, configurando-se como um programa estabelecedor de uma estrutura hierárquica mais ágil e funcional, promovendo a descentralização administrativa. Os gerentes da empresa submeteram-se a novos processos seletivos, fazendo com que muitos deles não conseguissem manter seus cargos em comissão, ocasionando uma grande tensão e atingindo a estabilidade imaginária dos funcionários. Como lembra um dos gestores entrevistados:

alguns programas que foram implantados na empresa a partir de 1995 são mudanças estruturais, bem radicais e que realmente afetaram demais os funcionários a partir daquela época. (...) o PRC é que foi realmente a grande virada que mexeu com todos os funcionários. Mudou a estrutura de cargos em comissão, a forma de atuar das agências, implantou uma série de programas, foi a partir daí que essas mudanças se incorporaram no dia-a-dia dos funcionários (gerente de área de apoio 2/ 24 anos de empresa). 
Como parte desse Programa estava, também, a automação das agências e um maior direcionamento da empresa no sentido de atender ao mercado, visando competir com os bancos privados, no intuito de se configurar cada vez mais como banco múltiplo (DIEESE, 2001a). A partir dessa visão, a empresa passou a criar uma gama de produtos que deveriam ser vendidos pelos funcionários, iniciando-se pelos cargos gerenciais e, posteriormente, atingindo a todos os funcionários, como lembra um dos sujeitos que aderiram ao PADV:

a gente nunca foi acostumada a vender, a empurrar coisas pras pessoas, e o que os outros bancos já faziam. (...) Só que na $X$ a gente não tinha essa cultura. E quando começou, foi começando com os gerentes, que começaram a ser pressionados a vender aqueles produtos, e de uma hora pra outra a gente também começou a ser muito cobrado pra isso (supervisora/12 anos de empresa).

A partir de 1995, portanto, as ações de reestruturação da empresa $X$ tornaram-se mais intensas, como preparação para os PADVs que seriam implementados a partir de 1996. A referência feita ao PADV em contexto de reestruturação do trabalho permite que se depreenda, desde já, as mudanças enfrentadas pelos sujeitos da reestruturação do trabalho bancário, e que sujeitos tais mudanças constroem. Tal como refere Grisci (2001), o sujeito da reestruturação do trabalho bancário caracteriza-se como o que responde "eu faço, eu faço, eu faço" de modo imediato, a toda e qualquer demanda que se apresente, tratando-se de um trabalhador protótipo da flexibilidade, tido como contraponto do trabalhador massificado que o fordismo cunhou. Tal sujeito deve fazer frente às novas demandas do trabaIho imaterial, bem como apresentar características pessoais que se tornam necessárias ao desenvolvimento e à manutenção das novas relações de serviço, como descritas por Lazzaratto e Negri (2001). 
A reestruturação produtiva do trabalho bancário viabiliza-se no sentido do uso intensivo da tecnologia da informação nos processos de trabalho e de uma busca maior pela competitividade. Desde esta lógica, os clientes da X, embora apresentando resistências, por se tratar de um público muito diversificado, tiveram que se adaptar para a utilização dos canais alternativos, como os terminais de auto-atendimento, como ilustra a fala a seguir:

a X não quer entupir agências de clientes, então criam canais alternativos de atendimento, as salas, com aquelas máquinas de caixa rápido, e cartões, muitos cartões... que as pessoas muitas vezes não sabem usar... Isso é outro processo de mudança cultural da clientela que também não se faz de um dia pra outro, mas as metas são em cima disso, as metas contam com esses canais alternativos... e aí se cria uma série de dificuldades (gerente de filial de pessoal/24 anos de empresa).

Nesse sentido, concorda-se com a reflexão de Ferreira ${ }^{5}$ (2002), a respeito da reestruturação produtiva do setor bancário tomada como um processo de:

pulverização das atividades bancárias, e mudança da relação produtor-consumidor, uma vez que o espaçotempo do trabalho bancário é algo que não se confina mais somente no espaço do banco. É uma reestruturação espaço-temporal, uma deslocalização espaço-temporal. A reestruturação produtiva do trabalho bancário ultrapassa os limites e o tempo do próprio banco, atingindo a sociedade como um todo, uma vez que os clientes passam a efetuar os trabalhos anteriormente realizados pelos bancários.

5 José Maria Carvalho Ferreira, professor da Universidade Técnica de Lisboa, em workshop realizado através de convênio com a Universidade Federal do Rio Grande do Sul, no mês de setembro de 2002, na Escola de Administração/UFRGS e no Instituto de Filosofia e Ciências Humanas/UFRGS. 
Tal uso da tecnologia, disseminado também entre os clientes, é o exemplo do que Santos (2002) denomina de a tirania da informação e do dinheiro, uma vez que, sendo a empresa $X$ uma instituição bancária, acaba utilizando a informatização em larga escala, exigindo dos clientes a adaptação às suas regras que visam ao aumento de lucros e à maior acumulação.

Desde essa percepção, os clientes são afetados pela reestruturação produtiva do trabalho bancário, uma vez que, mesmo tendo dificuldades em consumir a subjetividade fabricada pelas novas formas de organizar o trabalho dos bancos, são forçados a uma mudança de cultura, a uma mudança de seus modos de utilizar os serviços do banco. Como também mencionado por Ruffeil (2002) em relação à outra instituição, nesta fase de mudanças clientes e funcionários acabam sendo afetados pelas reestruturações empreendidas pela $X$.

A partir do direcionamento para o mercado, a criação de produtos iniciou-se, em larga escala, na empresa X. Vários produtos foram criados, antecipando necessidades dos clientes. Essa oferta de produtos visava, além da manutenção da empresa no mercado, a criação de um ambiente ideológico e cultural do consumo, próprios do trabalho imaterial. Mais uma vez a reestruturação produtiva do trabalho bancário atua como uma fábrica de subjetividades, produzindo o consumidor antes mesmo de produzir os produtos ou serviços.

Acerca da reestruturação, Chanlat (1999, p. 53) analisa que "em nome da globalização e da competitividade é que as empresas lançaram-se nessas reestruturações na maioria das vezes radicais". No caso da empresa X, os processos de reestruturação implantados passaram, via de regra, pela redução de pessoal, o que acarretou sobrecarga de trabalho aos que permaneceram, como menciona um dos entrevistados, ao lembrar os colegas que permaneceram trabalhando na empresa: "nós fazíamos o serviço em oito ou nove, eles estão em cinco, então quer dizer, a gente chega lá, eles estão com dois telefones, cada um em um ouvido, quer dizer, eles estão sendo massacrados" (caixa executivo/23 anos de empresa). 
Como continuidade da estratégia de redução de pessoal, nos jornais internos da empresa, lê-se que foram efetuadas terceirizações de algumas áreas nos anos de 1998 e 1999. Uma parte do telemarketing em julho de 1998; atividades de engenharia, em dezembro de 1998; setores de cobrança, em fevereiro e junho de 1999; telemarketing receptivo, em agosto de 1999, além dos serviços de retaguarda. Essas terceirizações compreendem parte dos vinte mil funcionários dispensados nos últimos anos na empresa $\mathrm{X}$, como menciona a gerente de filial de pessoal $/ 24$ anos.

Durante o ano de 1999, intensifica-se a automação e os canais de auto-atendimento para os clientes, bem como a padronização e integração de processos. Entre elas, destacam-se: a implantação da rede de processos, divulgada como uma ação que trouxe mudanças estruturais que afetaram o organograma da empresa; maiores padronizações dos serviços, utilizandose de um novo modelo operacional para todos os pontos de venda; o anúncio do desenvolvimento do projeto de segmentação de clientes; o chamado "Projeto X Virtual", que se tratava de um projeto de intensificação de vendas de produtos pela Internet, chamado pela empresa de um novo canal de comercialização.

Em setembro de 1999, o jornal interno da empresa anunciava um novo modelo de relacionamento com os clientes, em que se lê: "os produtos bancários hoje são pré-definidos, mas num futuro próximo os bancos provavelmente irão oferecer produtos modulares, ou seja, darão ao cliente a oportunidade de montar um determinado produto de acordo com suas necessidades". Assim, com a idéia de aumentar a sua competitividade na sociedade financeirizada, a partir de janeiro de 2000, a empresa passa a adotar o modelo de segmentação de clientes.

O modelo de segmentação de clientes veio ao encontro do desejo da empresa de não "entupir" as agências, fazendo com que nelas adentrassem somente aqueles com potencial para consumir os produtos e serviços e que tivessem potencial de reciprocidade, ou seja, condições financeiras suficientes para investir na empresa. Além disso, são mencionados também como 
objetivos dessa nova forma de gestão, o estabelecimento e ampliação de canais de baixo custo para os segmentos pouco rentáveis (como salas de auto-atendimento), e o melhor aproveitamento das oportunidades de vendas cruzadas, uma vez que cada cliente participa de uma carteira específica, o que facilita o controle de seus negócios. Para Ruffeil (2002, p.161), o modelo de segmentação permite:

que a massa populacional de clientes espalhados em todo o território nacional possa ser recortada em subgrupos que, por sua vez, podem ser segmentados a partir de determinadas tendências e os indivíduos, distribuídos em uma curvatura de comportamentos, hábitos de consumo, qualificações, possibilitando trabalhar tendências e intenções.

Trabalhar com o modelo de segmentação de clientes passou a exigir dos sujeitos de forma mais intensa aquelas características demandadas pelo trabalho imaterial, tal como apontam os autores que tratam do tema (COCCO, 2000; PELBART, 2000; LAZZARATO e NEGRI, 2001; HARDT e NEGRI, 2001; LAZZARATTO, 2002). Tais características dizem de uma mobilização afetiva no sentido de antecipar as necessidades do cliente, ou até mesmo, criar-lhe a necessidade do bem imaterial, que é a relação de serviço.

O modelo de segmentação determina uma profunda mudança na organização do trabalho, na empresa $X$, uma vez que implica uma nova reestruturação da empresa como um todo. A partir desse modelo, os pontos de vendas foram reestruturados relativamente aos aspetos físicos, tecnológicos e de pessoal. A divisão do trabalho e a divisão de homens (DEJOURS, 1994) são alteradas, no sentido em que os funcionários são dispostos de forma a atenderem o público separadamente, sem perder a possibilidade de realizar vendas.

Com a reestruturação das salas de auto-atendimento, surgiu o bancário temporário contratado por um período específico de tempo cuja principal 
tarefa é fazer com que os clientes utilizem, de forma intensiva, os chamados canais alternativos de atendimento. Nesse sentido, pode-se concordar com as palavras de Santos (2002) quando afirma que as empresas, visando atender os reclamos da finança e buscando manter-se competitivas no mercado global, acabam negligenciando aspectos sociais e deteriorando o emprego. Isso se faz notar no fato de que trabalhadores temporários percebem salário inferior ao dos demais trabalhadores, não possuem benefício algum e são demitidos ao término do período de seis meses.

A segmentação de clientes, implementada pela empresa X, configura-se como dois modos de gestão complementares: a gestão da intimidade e a gestão do anonimato (GRISCI, 2002; RUFFEIL, 2002). Tais modos de gestão se destacam na seguinte frase presente em documento interno da empresa: "tratar grupos diferentes de formas diferentes". Nesse sentido, a gestão da intimidade está relacionada aos grupos pertencentes ao segmento integral e personalizado que são os clientes com maiores rendas e maiores volumes de negócios com a empresa. Em relação a esses clientes, a estratégia da empresa é conhecer o maior número possível de dados referentes à sua intimidade, visando à venda de produtos específicos, uma vez que esse grupo possui maior poder de compra.

A gestão do anonimato possibilitada pelos recursos da tecnologia que desconhece nomes, rostos, mas que, no entanto, auxiliado pela velocidade e pela presença em diversos espaços, permite atender a um número ilimitado de pessoas, distanciado-as do acesso direto e físico às agências bancárias e aos trabalhadores bancários. Nesse sentido, para haver a personalização no atendimento de alguns, faz-se necessária a despersonalização de outros.

Paralelo à implantação do modelo de segmentação de clientes, no ano de 2000, foi realizado um concurso público para contratação de funcionários na empresa X, sendo que o anterior ocorrera em 1989. A realização de tal concurso foi percebida como uma estratégia da empresa que visava levar os sujeitos a uma desestabilização, como ilustrado na fala de um dos entrevis- 
tados: "a empresa abriu um concurso, aprovou um monte de gente e deixou na espera, ameaçando o pessoal, que quem não trabalhasse, ela mandaria embora e chamaria outros" (caixa executivo/22 anos de empresa). A peculiaridade deste concurso é que os novos cargos, agora designados técnicos bancários, apresentavam características e salários distintos dos demais funcionários:

os técnicos bancários são diferentes, eles entram na X sabendo que a atuação deles será pra vendas. Que vão todos pras agências e que lá terão que fazer vendas. O salário, também, é muito abaixo dos escriturários. ${ }^{6}$ Eles ganham no mínimo $50 \%$ menos, em relação aos escriturários que estejam em uma referência mais alta, a diferença do técnico bancário pra um escriturário em uma referência alta, chega a ser quatro vezes. Ainda assim, é um salário mais alto que o do mercado. Então, o escriturário é um funcionário muito caro para a X (gerente de área de apoio/12 anos de empresa).

A contratação dos técnicos bancários, em condições diferenciadas dos atuais funcionários, fez com que na empresa se configurasse a presença de dois grupos de trabalhadores: os antigos e os novos. Os novos, conforme mencionado por um dos entrevistados, assumem o projeto da empresa e "vestem a camisa": "os guris novos, que entraram no ano passado, já estão assumindo função gerencial. Claro que esse pessoal já entra com mais pique, mais qualificado e estão assumindo como gerentes" (escriturário/12 anos de empresa). Tal estratégia, portanto, fez com que a divisão dos trabalhadores dentro da organização do trabalho fosse afetada, tendo estabelecido, na empresa, uma segmentação do grupo de trabalhadores.

6 Escriturário era a designação anteriormente utilizada para os bancários que não possuíam cargos em comissão (gerentes, caixas, etc.). As referências, que vão de 35 (a menor) até 98 (a maior), referem-se ao Plano de Carreira existente anteriormente, sendo que não se encontra mais em vigência. 
Ainda em 2000, seguindo a estratégia da empresa de cortar custos, foi implementada uma segunda edição do PADV que tinha como públicoalvo escriturários sem função de confiança, ou seja, sem cargos de gestão, e os caixas executivos. Nesta edição, a empresa conseguiu "desligar 10\% de seu público-alvo, o que foi considerado um bom percentual" (analista pleno/26 anos de empresa).

Como continuidade às mudanças caracterizadas como desterritorializantes, conforme menciona Grisci (2000, p. 8), pois "provocam desassossego e atingem aqueles sujeitos ditos dos postos de gestão, tanto quanto aqueles dos postos de execução, (...), inscrevem-se no tempo da velocidade, arrancando os sujeitos de territórios solidificados", pode-se mencionar um novo aspecto da reestruturação que teve início em 2001 e trouxe consigo a terceira edição do PADV. Tal reestruturação simbolizou a nova forma de gestão da empresa que buscava a centralização dos processos das áreas de apoio (logística, suprimentos, recursos humanos, etc.) em Brasília, com extinção das filiais regionais, que existiam nos estados.

Com a extinção das filiais, os funcionários dessas gerências tiveram diferentes destinos: desligamento da empresa, por ocasião dessa terceira edição do PADV; aposentadoria; transferência para as agências, visando concentrar a atuação em vendas; ou transferência para Brasília, para atuar junto às centralizadoras (unidades criadas em Brasília, para concentrar as atividades das áreas). A centralização é analisada, em matéria publicada pelo jornal da associação de pessoal da X, como uma ameaça aos bancários que teriam que se deslocar a lugares distantes, transferidos para os locais onde existiam vagas disponíveis e ainda como uma desestruturação da integração existente entre os bancários.

A partir de julho de 2001, a empresa X passou por um novo processo de mudança, dessa vez procurando adaptar-se a um acordo internacional que regula as atividades bancárias, chamado Acordo de Basiléia. Trata-se de 
um acordo adotado por um comitê de bancos centrais e reguladores, gestores bancários dos maiores países industrializados que se reúnem a cada três meses no Banco de Compensações Internacionais, na Basiléia, Suíça. O Comitê fornece orientações da política que os gestores de cada país podem usar para determinar políticas gestoras aplicadas no e pelo sistema bancário. Tais estudos são projetados na expectativa de que sejam seguidos pelos gestores de todo o mundo.

Os programas de redução de custos adotados a partir dessas resoluções, como indicado pelo jornal das associações de pessoal da X, passavam, via de regra, por redução de funcionários, visando maior rentabilidade e menores custos. Foi nesse sentido que, entre setembro e outubro de 2001, ocorreu a terceira edição do PADV. O referido PADV teve como públicoalvo todos os funcionários da empresa, com exceção dos técnicos bancários, funcionários novos contratados a partir de concurso realizado em 2000. Nesse PADV, poderiam aderir, portanto, também funcionários ocupantes de cargos de gestão, como de fato ocorreu, com a saída de gerentes gerais, gerentes de relacionamento, gerentes de atendimento e supervisores (14 ao todo, entre o grupo pesquisado de 104 sujeitos). O PADV tornou-se um dos elementos importantes à compreensão de como a reestruturação produtiva do trabalho afetou os modos de trabalhar e de ser dos trabalhadores bancários.

Visando ilustrar o que foi mencionado até aqui, acerca das principais mudanças ocorridas na empresa $X$, apresenta-se a Figura 1. 
Sociologias, Porto Alegre, ano 6, no 12, jul/dez 2004, p. 160 -200

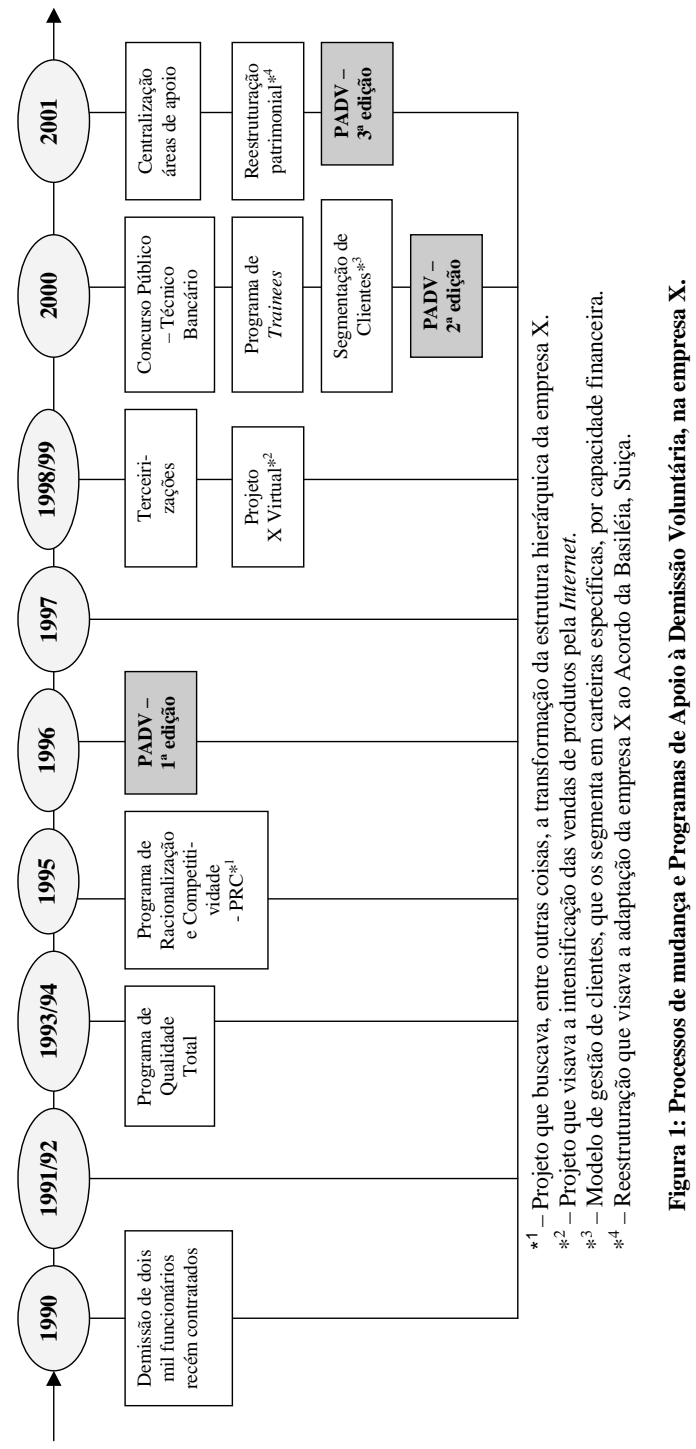


4 Modos de trabalhar e de ser proveniente da reestruturação produtiva do trabalho bancário

As mudanças apresentadas e analisadas até então produziram naqueles que permaneceram em seus postos de trabalho, não aderindo aos PADVs de 1996, 2000 e 2001, subjetividades que proclamam novos modos de ser e de agir perante o trabalho. Os três fenômenos sociais que caracterizam o processo de reestruturação nos bancos - intenso desemprego, terceirização e precarização do trabalho, e intensificação do trabalho - imbricados à questão da "nova qualificação do bancário", de acordo com os estudos realizados por Segnini (1999) se fizeram notar também na empresa X. A organização do trabalho intimamente relacionada a tais fenômenos, além de desencadear pressões externas, desencadeia pressões internas ao próprio sujeito, de modo a fazer frente a esse novo ambiente mais competitivo e voltado ao mercado. Nesse sentido, aliados à intensificação do trabalho advinda da redução de funcionários, processos de doenças ocorreram gerando problemas de Lesão por Esforço Repetitivo - LER - ou Doenças Ocupacionais Relacionadas ao Trabalho - DORT, como mostra Penella (2000). A impossibilidade de resolver ou mudar a organização do trabalho (DEJOURS, 1994), faz com que os problemas sejam agravados, como mencionado a seguir:

os últimos dois anos como caixa executivo me trouxeram muitas dores nas costas, em virtude da postura prejudicada. Às vezes, ficava horas atendendo a fila sozinha, outras vezes em dois caixas e raramente ficava a bateria completa de três caixas. Ouvíamos muitas reclamações na fila que gerava uma tensão adicional às condições de trabalho (escriturário/23 anos de empresa).

A fala apresentada permite ainda depreender que, embora a empresa esteja realizando um esforço acentuado para impedir o acesso de um número elevado de pessoas ao interior das agências, as filas permanecem. Isso se deve ao fato de a empresa trabalhar com um público variado de 
clientes (que possuem conta ou que simplesmente vão até o banco para receber algum benefício social) e da dificuldade que um grande número deles possui de absorver as inovações tecnológicas. Ainda como fator que colabora com a intensificação do trabalho aparece a redução no número de caixas, como mencionado por um dos entrevistados:

entrou o projeto para diminuir o número de caixas, fazer os clientes usarem mais máquinas, mudou significativamente, foi um choque cultural muito grande dentro da $X$, já era um modelo que os outros bancos estavam operando há mais tempo, os bancos privados principalmente, então foi um choque pra clientela e foi um choque interno muito grande (gerente de atendimento/ 11 anos de empresa).

Os processos de reestruturação do trabalho bancário, até então mencionados, acarretaram novos modos de trabalhar já que demandaram dos bancários uma atuação intensiva em vendas e, portanto, criaram novos modos de subjetivação aos quais os trabalhadores bancários ficaram expostos. Para os bancários mais antigos, tais modos de subjetivação não se mostraram indolores pois eles foram construídos num trabalho bancário de outra natureza, mais burocratizado e sem a necessidade da atuação como vendedores. A idéia socialmente construída de pertencer a um grupo de privilegiados (ACCORSI, 1990), perdeu-se em um tempo não tão distante, uma vez que, mesmo para aqueles que aderiram ao PADV e que tinham menos tempo de empresa, a idéia de trabalhar em uma instituição pública, como a $\mathrm{X}$, se mostrava atraente, por ocasião do ingresso. ${ }^{7}$

Esse cenário levou os trabalhadores bancários a questionarem sua sobrevivência enquanto categoria, agravada a cada vez que a mídia divulga matérias que dizem de extinção da categoria dos bancários (LAZZAROTTO,

7 Cabe ressaltar que o concurso público ocorrido anteriormente ao de 2000, foi no ano de 1989. Portanto, os sujeitos que aderiram ao PADV e que possuíam menos tempo de empresa, tinham em torno de 12 anos de trabalhos prestados, uma vez que aqueles que ingressaram a partir de 2000 não poderiam aderir ao programa. 
2002). O questionamento não se restringiu apenas ao coletivo, afetando particularmente o sujeito que se comparava a uma "massa velha" ou a animais, como ilustrado nessa fala de um dos entrevistados: "imagina eu, um caixa executivo, 22 anos de empresa, qualquer macaco bem treinado faria o que eu faço. É, é assim, só falta eles dizerem 'qualquer macaco bem treinado faz o que tu fazes'"' (caixa executivo/22 anos de empresa).

Como relatado por Ruffeil (2002), este sentimento pode ser caracterizado como um esvaziamento do trabalho, oriundo da inserção intensa da tecnologia nos processos de trabalho, aqui destacado na função de um caixa executivo que teve seu trabalho profundamente modificado pela tecnologia. Tal sentimento faz-se ainda mais penoso quando os sujeitos se recordam da sua entrada na empresa, que em geral se deu por influência de familiares que lá trabalhavam, ou pela busca de boas condições de salário e de emprego, com cargas horárias reduzidas. Se, em sua grande maioria, no entanto, entraram na empresa por acaso, lá permaneceram por desenvolver uma relação simbiótica com a mesma. Tal como mencionam Pagès et al. (1993), a empresa, nessa relação, adquiriu a representação de mãe, provedora e protetora de seus filhos-funcionários: "a $X$ teve sempre pra gente uma imagem de um útero. O útero é uma coisa boa, ele protege, ele nutre, mas o útero também separa todo o mundo externo, de certa forma" (escriturário/12 anos de empresa).

Da representação da $\mathrm{X}$ enquanto mãe, os sujeitos passaram à representação de uma empresa que os tratou como números, como máquinas ou como "massa velha". A mãe deixou de existir e, em seu lugar, surgiu uma saudosa recordação dos tempos idos, cujo reviver é impossível, como bem o sabem os próprios sujeitos: "a saudade já existia de outra época, era uma coisa nostálgica, de outra época" (avaliadora executiva/26 anos de empresa).

A maneira como a empresa está sendo administrada atualmente é responsabilizada pelos sujeitos como geradora dos seus sofrimentos. Das 
falas dos sujeitos pesquisados, depreende-se um sentimento generalizado de que a atual política de gestão de pessoas os trata unicamente como números, quer seja o número de sua matrícula, o número resultante de suas vendas ou o número de ordem da máquina (computador) à qual estão conectados.

\section{Considerações finais}

As transformações na organização do trabalho experimentadas pelo setor bancário foram, inicialmente, lentas e graduais. Entretanto, com o uso intensivo das novas tecnologias de automação bancária e de novas formas de gestão do trabalho, essas mudanças passaram a ocorrer em maior velocidade. Os trabalhadores bancários passaram a submeter-se à velocidade, auxiliados pelas novas tecnológicas, necessitando, com isso, adaptar-se às mudanças.

Os modos de trabalhar advindos do modelo de segmentação dos clientes e do direcionamento da empresa $\mathrm{X}$ ao mercado, acarretando a cobrança exacerbada de metas, despertou nos sujeitos a idéia de serem recursos utilizáveis apenas para o atingimento de um determinado fim. As metas e o propósito final de lucro acabam ocupando os espaços dos sujeitos nas prioridades traçadas pela empresa.

Com a crescente importância da atividade das instituições financeiras e a necessidade de manter-se forte em um mercado instável, a empresa $\mathrm{X}$, tal como as demais empresas prestadoras de serviços bancários, passou a demandar de seus funcionários características que remetem ao trabalho imaterial que requer uma mobilização de afetos no sentido de fidelizar o cliente, de lhe criar necessidades, de antever seus desejos. Instalou-se, portanto, um paradoxo, visto que o sujeito do trabalho é chamado a ser ator fundamental do processo de trabalho, mas é tratado como um simples recurso, reduzido a "capital fixo" (LAZZARATTO e NEGRI, 2001, p. 30). 
Especialmente para os bancários antigos, tais exigências causam desconforto, uma vez que, diferentemente dos novos, os antigos representam um grupo que consumiu subjetividades produzidas em um outro modo de trabalhar, em um outro tempo e em uma outra relação com a empresa. Num tempo que dizia de um bancário detentor de uma condição privilegiada, representante de uma categoria que dispunha de um status social diferenciado perante a sociedade.

Assim, apesar de toda a exigência de mobilização subjetiva dos trabaIhadores por parte da empresa, como uma das características do trabalho imaterial, parece que os sujeitos, em especial os mais antigos, carecem de que a gestão de pessoas os tome como sujeitos que realmente são. A impessoalidade está presente nas relações que a empresa $X$ passou a estabelecer com um segmento de sua clientela, que não possui recursos financeiros suficientes, de modo a lhes permitir consumir em larga escala os produtos do banco. Na impessoalidade da gestão relativa aos funcionários, o computador é colocado em cena, como ator principal, no momento em que as atividades, antes executadas pelos bancários, passaram a ser realizadas, em grande parte, pelos clientes, nos terminais de auto-atendimento.

A empresa $\mathrm{X}$ incorporou às políticas direcionadas aos clientes e às políticas de gestão de pessoas, a exigência de reciprocidade. No que diz respeito aos clientes, a reciprocidade relaciona-se aos aportes financeiros que estes possam direcionar à empresa e ao número de produtos que possam comprar. No que tange aos bancários, a reciprocidade relaciona-se à lucratividade que possam auxiliar a gerar, como resultado das vendas efetuadas e das relações de serviço estabelecidas com os clientes, as quais tenham possibilidades de retorno. O investimento que a empresa deseja, por parte dos sujeitos do trabalho, para que eles possuam tal reciprocidade, diz de uma mobilização subjetiva total e incondicional ao seu projeto e aos objetivos de lucratividade.

A mercantilização das relações estende-se entre os bancários, incentivados pela exacerbação do individualismo e pelas políticas de gestão da 
empresa, deixam de lado a solidariedade, dedicando-se com ainda mais afinco às suas atividades. Assim, os novos modos de trabalhar bancário (re)constroem uma categoria fragmentada, em que as relações são permeadas pela individualidade, evidenciada na ausência de colaboração entre colegas.

A performance parece ter sido uma característica muito demandada aos sujeitos do trabalho na empresa X. A performance nas vendas, nas relações de serviços e, principalmente para os ocupantes de postos ditos de gestão, no atingimento das metas. A gestão da empresa X pode ser visualizada como a gestão da excelência, uma vez que, atualmente, baseia-se na noção de produzir melhor que os concorrentes, enfatizando a primazia do êxito e a adaptabilidade a desafios permanentes, advindos dos constantes processos de reestruturação produtiva do trabalho.

\section{Referências}

ACCORSI, André. Automação: bancos e bancários. 1990. 127 f. Dissertação (Mestrado em Administração) - Universidade de São Paulo, São Paulo.

ANTUNES, Ricardo. Adeus ao trabalho? Ensaio sobre as metamorfoses e a centralidade do mundo do trabalho. São Paulo: Cortez, 2000.

ANTUNES, Ricardo. Os sentidos do trabalho. Ensaio sobre a afirmação e a negação do trabalho. São Paulo: Boitempo, 2001.

BESSI, Vania G.. Subjetividade em tempos de reestruturação produtiva do trabalho bancário e programa de apoio à demissão voluntária. 2003. 166 f. Dissertação (Mestrado em Administração) - Escola de Administração, Universidade Federal do Rio Grande do Sul, Porto Alegre.

CASTEL, Robert. As metamorfoses da questão social - uma crônica do salário. Petrópolis: Vozes, 1998.

CASTELLS, Manuel. A Sociedade em rede. São Paulo: Paz e Terra, 2000. 
CHANLAT, Jean-François. Por uma antropologia da condição humana nas organizações. In: CHANLAT, J.(org.). O indivíduo na organização: dimensões esquecidas. São Paulo: Atlas, 1996. v.1.

CHANLAT, Jean-François. Ciências Sociais e Management: Reconciliando o EConômico e o Social. São Paulo: Atlas, 1999.

CHANLAT, Jean-François. Modos de gestão, saúde e segurança no trabalho. In: DAVEL, Eduardo; VASCONCELOS, João M. (Org.). Recursos humanos e subjetividade. Petrópolis: Vozes, 2000.

COCCO, Giuseppe. Trabalho e cidadania. Produção e direitos na era da globalização. São Paulo: Cortez, 2000.

COCCO, Giuseppe. Introdução. In: LAZZARATO, Maurizio. e NEGRI, Antonio. Trabalho imaterial: formas de vida e produção de subjetividade. Rio de Janeiro: DP\&A, 2001.

CORAZZA, Gentil. Crise e reestruturação bancária no Brasil. Porto Alegre: Editora UFRGS, 2000.

COSTA, Fernando N. da. Êxodo dos bancários. Disponível em < http:// www.fenag.org.br/leitura/messages/66.html> Acesso em: 08 nov. 2001.

DAVEL, Eduardo e VERGARA, Silvia C. Gestão com pessoas, subjetividade e objetividade nas organizações. In: DAVEL, Eduardo e VERGARA, Silvia C. (org.). Gestão com pessoas e subjetividade. São Paulo: Atlas, 2001.

DEJOURS, Christophe et al.. Psicodinâmica do trabalho - contribuições da escola dejouriana à análise da relação prazer, sofrimento e trabalho. São Paulo: Atlas, 1994.

DIEESE. A situação do trabalho no Brasil. Produzido pelo DIEESE - São Paulo: 2001.

DIEESE. Conjuntura, resultados, remuneração e empregos: subsídios para discussão na 3a Conferência Nacional dos Trabalhadores do Ramo Financeiro. Elaborado pelo DIEESE - Linha Bancários. São Paulo: DIEESE, 2001a. 
DIEESE: Banco de dados. Disponível em: <http://www.dieese.org.br/>. Acesso em 15 nov. 2001b. FEBRABAN: banco de dados. Disponível em < http:// www.febraban.com.br> Acesso em : 15 nov. 2001.

FERREIRA NETO, João Leite. Subjetividades contemporâneas: algumas contribuições de Deleuze. Revista Plural, Belo Horizonte, n.13, p.105-113, mar. 2000.

FORRESTER, Viviane. O horror econômico. São Paulo: Universidade Estadual Paulista, 1997.

GONÇALVES FILHO, Cid. Reestruturação produtiva, qualificação e trabalho no Brasil: uma análise crítico-reflexiva. Revista Plural, Belo Horizonte, n.13, p.22-43, mar. 2000.

GRISCI, Carmem L.I. Trabalho, tempo e subjetividade: a reestruturação do trabaIho bancário. 2000. 314 f. Tese (Doutorado em Psicologia) - Pontifícia Universidade Católica do Rio Grande do Sul, Porto Alegre.

GRISCI, Carmem L.I. Dos corpos em rede às máquinas em rede: reestruturação do trabalho bancário e constituição do sujeito. In: ENAMPAD, XXV, 2001, Campinas. Anais... Campinas, 2001. 1 CD-Rom.

GRISCI, Carmem L.I. Trabalho, gestão e subjetividade em tempos de reestruturação do trabalho bancário. Porto Alegre: FAPERGS, 2002.

HARDT, Michael e NEGRI, Antonio. Império. 2.ed.. Rio de Janeiro: Record, 2001. HARVEY, David. Condição pós-moderna. São Paulo: Loyola, 2001.

JINKINGS, Nise. O mister de fazer dinheiro: automação e subjetividade no trabalho bancário. São Paulo: Boitempo, 1996.

KREIN, José Dari e NEUTZLING, Inácio. As Mudanças no Mundo do Trabalho: Características da Reestruturação Produtiva. Curitiba: CEPAT, 1995.

LARANGEIRA, Sônia M. G. Reestruturação produtiva no setor bancário: a realidade dos anos 90. Educação \& Sociedade, v. 18, n.61, p. 110-138, dez.1997. 
LAZZARATO, Maurizio e NEGRI, Antonio. Trabalho imaterial: formas de vida e produção de subjetividade. Rio de Janeiro: DP\&A, 2001.

LAZZAROTTO, Gislei D. R.. Modos de Experimentar o Não-trabalho: Desemprego no Contexto da Reestruturação Bancária. In: FONSECA, Tânia Mara Galli (org.). Modos de trabalhar, modos de subjetivar. Porto Alegre: UFRGS, 2002.

LIMA, Maria Elizabeth A. Os equívocos da excelência: as novas formas de sedução na empresa. Petrópolis: Vozes, 1995.

MARUCCI, José Carlos e MACHADO-DA-SILVA, Clóvis L. Contexto ambiental e esquemas interpretativos: análise do posicionamento estratégico de bancos COmerciais. In: ENANPAD, XXIV, 2000, Florianópolis. Anais... Florianópolis, 2000. 1 CD-Rom.

NAFFAH NETO, Alfredo. Outr'em-mim: ensaios, crônicas, entrevistas. São Paulo: Plexus, 1998.

PAGÈS, Max et al... O poder das organizações. São Paulo: Atlas, 1993.

PELBART, Peter Pal. A vertigem por um fio: políticas de subjetividade contemporânea. São Paulo: FAPESP Iluminuras, 2000.

PENELLA, Isabela. LER: uma jornada de sofrimento no trabalho bancário. 2000. 198 f. Dissertação (Mestrado em Sociologia) - Universidade de São Paulo. São Paulo, 2000.

POCHMANN, Marcio. O mundo do trabalho em mudança. In: NABUCO, Maria Regina e CARVALHO NETO, Antonio (orgs.). Relações de Trabalho Contemporâneas. Belo Horizonte: IRT da PUC de MG, 1999.

RUFFEIL, Neide Regina S.. A reestruturação produtiva numa instituição financeira: novos modos de trabalhar e subjetivar. 2002. 201 f. Dissertação (Mestrado em Psicologia). Centro de Estudos Gerais - Universidade Federal Fluminense. Niterói, 2002. 
SALINAS, José Luis, MAÇADA, Antonio Carlos G. e SANTOS, Marli Elisabeth R. dos. Mudança radical em organizações complexas: o caso do Banco do Brasil. In: ENANPAD, XXII, 1998, Foz do Iguaçu. Anais... Foz do Iguaçu, 1998. 1 CD-Rom.

SANTOS, Milton. Por uma outra globalização: do pensamento único à consciência universal. 9. ed. Rio de Janeiro: Record, 2002.

SEGNINI, Liliana R.P. Mulheres no trabalho bancário: difusão tecnológica, qualificação e relações de gênero. São Paulo: Ed. da Universidade de São Paulo, 1998.

SEGNINI, Liliana R.P.. Reestruturação nos bancos no Brasil: desemprego, subcontratação e intensificação do trabalho. Educação \& Sociedade, v. 20, n. 67, p.183-209, ago. 1999.

YIN, Robert K. Estudo de caso - planejamento e métodos. Porto Alegre: Bookman, 2001.

Recebido: 18/03/2004

Revisado: 13/04/2004

Aceite final: 02/06/2004 


\section{Resumo}

O artigo discute como a reestruturação produtiva do trabalho bancário afetou os modos de trabalhar e de ser dos trabalhadores de uma centenária instituição bancária pública que implementou Programas de Apoio à Demissão Voluntária como uma das novas ferramentas de gestão. Trata-se de um estudo de caso que investigou 104 trabalhadores dos estados do Rio Grande do Sul e de Santa Catarina que aderiram à terceira edição de um desses Programas, ocorrido na empresa em 2001, além de cinco gestores e três funcionários da área de Recursos Humanos da empresa diretamente envolvidos com os Programas ou com os desligados. A coleta de dados deuse através de questionário, entrevistas individuais semi-estruturadas e fontes documentais. Os dados coletados foram submetidos à análise de conteúdo. Os resultados da pesquisa indicam que a reestruturação produtiva do trabalho bancário demarca a passagem de uma cultura de estabilidade e segurança para uma cultura de instabilidade e insegurança que afeta os modos de trabalhar e de ser dos bancários. O investimento que a empresa deseja, por parte dos sujeitos do trabalho diz, portanto, de uma mobilização subjetiva total e incondicional ao seu projeto e aos objetivos de lucratividade.

Palavras-chave: reestruturação produtiva do trabalho, organização do trabaIho, trabalho bancário, subjetividade. 